\title{
Factors of Nephroblastomas' Relapse in Children at the Academic Hospital Gabriel Toure, Bamako, Mali
}

\author{
Djénèba Konaté ${ }^{*}$, Coulibaly Yacaria², Doumbia Abdoul Karim¹, Doumbia Aliou ${ }^{2}$, Amadou Issa², \\ Oumar M. Coulibaly², Traoré Fousseyni' ${ }^{1}$, K. Traoré1, Kamaté Bénoi², Djiré Mamadou Kassoum², \\ Coulibaly Youssouf ${ }^{2}$, Traoré Abdramane², Togo Pierre1, Koné Oumou ${ }^{3}$, Togo Boubacar'
}

${ }^{1}$ Service of Pediatrics, Teaching Hospital Gabriel Touré, Bamako, Mali

${ }^{2}$ Service of Pediatric Surgery, Teaching Hospital Gabriel Touré, Bamako, Mali

${ }^{3}$ National Public Health Research Institute, Bamako, Mali

Email: *djeneba.konate@yahoo.fr

How to cite this paper: Konaté, D., Yacaria, C., Karim, D.A., Aliou, D., Issa, A., Coulibaly, O.M., Fousseyni, T., Traoré, K., Bénoi, K., Kassoum, D.M., Youssouf, C., Abdramane, T., Pierre, T., Oumou, K. and Boubacar, T. (2020) Factors of Nephroblastomas' Relapse in Children at the Academic Hospital Gabriel Toure, Bamako, Mali. Open Journal of Pediatrics, 10, 131-136.

https://doi.org/10.4236/ojped.2020.101012

Received: January 29, 2020

Accepted: February 9, 2020

Published: February 12, 2020

Copyright $\odot 2020$ by author(s) and Scientific Research Publishing Inc. This work is licensed under the Creative Commons Attribution International License (CC BY 4.0).

http://creativecommons.org/licenses/by/4.0/ (c) (i) Open Access

\begin{abstract}
Introduction: The factors of nephroblastomas' relapse are a set of elements playing a role in the reappearance of cancer cells in the same place of the kidney or in other regions of the body after a 5 -year remission. Objectives: To determine the frequency and the factors of nephroblastomas' relapse in the pediatric oncology unit and pediatric surgery of the academic hospital Gabriel Touré. Materials and methods: This was a retrospective study carried out from January 1, 2005 to December 31, 2019 in all children treated for nephroblastoma relapses in the pediatric oncology unit and in the pediatric surgery service. Results: In 15 years, we have managed 182 cases of nephroblastoma, of which 128 cases were declared in complete remission after 5 years and 12 cases presented a recurrence. The relapses factors were: capsular break, intraoperative tumor rupture, presence of an associated malformation, surgery without neoadjuvant chemotherapy and tumor surgical stage $(p<$ 0.05). Patients' age at diagnosis, sex, number of neoadjuvant and adjuvant chemotherapy sessions and histological type were not decisive $(p>0.05)$. Conclusion: Relapses are more and more frequent in cases of nephroblastoma. The correct use of the protocol would avoid these recurrences.
\end{abstract}

\section{Keywords}

Nephroblastoma, Relapse, Factors, Children, Mali

\section{Introduction}

Nephroblastoma or Wilms tumor is a malignant tumor developed from embryonic tissues of the kidney (metanephrotic blastema). It is almost child-specific and 
occurs frequently between 1 and 5 years of age [1]. It is one of the childhood tumors that have most benefited from the progress of oncology over the past 10 years with treatments leading to healing without sequelae in around $90 \%$ of cases [2]. However, this management is confronted to many difficulties in an underdeveloped environment, namely: delayed diagnosis, discontinuation of treatment before complete remission, drug shortages and often lack of radiotherapy. These difficulties can lead to recurrence. It is defined as the reappearance of signs after the patient has been declared cured. The frequency of these recurrences varies from $5.5 \%$ to $29 \%$ [3] [4]. Their management follows the same rules as nephroblastoma and their prognosis is poor [5]. Relapses' factors are a set of elements that play a role in the reappearance of cancer cells in the same place of the kidney or in other areas of the body after complete remission [5]. Since 2005, our oncology unit takes care of Wilms tumor according to the recommendations of the Franco-African Group of Oncology. Some cases of relapses exist. We conducted this work in order to study the relapses' factors in our daily practice.

\section{Objectives}

To determine the frequency and factors of nephroblastomas' relapse.

\section{Methodology}

This was a retrospective study carried out from January 1, 2005 to December 31, 2019 in the Oncology Unit of the pediatric service and the pediatric surgery service of the academic hospital Gabriel Touré in Bamako. It focused on all cases of nephroblastoma treated and declared cured according to the protocol of the Franco-African Group of Pediatric Oncology (GFAOP). All cases of nephroblastoma relapse were included in this study. Cases of nephroblastoma undergoing treatment or in remission and other renal tumors were not included in the study. The studied parameters were: age, sex, histological type, chemotherapy, surgical incidents (capsular breach, tumor rupture), quality of the excision and stage of surgical extension. The data were analyzed on SPSS software version 10.0). The statistical tests used were Chi-square and Fisher's exact test with a significance level of $p<5 \%$.

\section{Results}

In 15 years, 182 cases of Wilms' tumor were identified among which 128 cases were declared cured. Among these cases declared in complete remission, 12 patients presented a relapse. This was a recurrence rate of $9.3 \%$. The recurrence concerned 5 boys and 7 girls (compared to 57 boys and 59 girls without relapse with $(p=0.8496)$ ). The sex ratio was 0.7 . The mean age of these patients was 5.4 \pm 2 years with extremes of 7 and 13 years. The recurrence concerned 9 children aged between 7 and 10 years against 73 cases of non-recurrence $(p=0.5352)$. The socioeconomic level was low in 8 cases for recurrences compared to 88 cases 
of non-recurrence $(p=0.4931)$. The tumor was of high risk in 6 cases of recurrence against 49 , intermediate in 4 cases against 54, and undetermined in 2 cases against 13 ( $p=0.6543)$. The adjuvant chemotherapy protocol was correct in 10 cases of recurrence versus 115 cases of non-recurrence $(p=0.0230)$. At the end of treatment, the mean time to recurrence was 4.38 months with extremes of 2.5 and 15 months. Ultrasound revealed mass in 9 cases and computed tomography in 3 cases. Recurrence was only local intraabdominal in 9 cases (75\%) and associated with metastasis in 3 cases (25\%). The metastases were hepatic, pulmonary and lymph node. Associated factors to relapse are summarized in Table 1. Those factors were the presence of associated malformations chemotherapy protocol, the quality of surgery and the tumor surgical stage. A protocol of chemotherapy associated to radiotherapy was initiated in two patients while the other followed chemotherapy. No death was registered.

\section{Comments and Discussion}

During this work certain difficulties were encountered. There were about the poor storage of medical record, the lack of certain data in the file and the non-compliance with control appointment.

Despite great efforts in the management of Wilms' tumor, relapses are possible after a complete remission. In developing countries the recurrence rate varies from $15 \%$ to $20 \%$ [6]. We have found $9.3 \%$ recurrence rate. It was about $17.8 \%$ in the series of Aoba et al. [7]. In $80 \%$ of cases relapses occur within 2 years after the first diagnosis [8]. The mean time to relapse was 4.38 months in our series. In the series of Rodriguez Iglesias et al. [9] cases of relapse appeared before one year. The etiology of nephroblastoma's relapse is not clearly known, however some hypotheses have been cited such as uncontrolled cellular growth (insufficient immune response), vascularization limited to a tumor portion and the dependence of cells on growth factors [10].

Relapse factors are a set of elements that play a role in the reappearance of cancer cells in the same place of the kidney or in other areas of the body after complete remission [5]. In our study a few factors were decisive.

\subsection{Associated Malformations}

A wide range of syndromes, congenital anomalies and constitutional chromosomal abnormalities are known to be associated with Wilms tumor [11]. These are particularly Wiedemann-Beckwith syndrome, Denys-Drash syndrome, Fanconi and WAGR in $3.8 \%$ to $4.7 \%$ [12] [13]. The frequency of these malformations varies between $8 \%$ and $17 \%$ [13]. We have recorded three cases of aniridia and two cases of polycystic kidneys. Among those five cases with malformation four had relapsed. However these numbers of malformation are not enough to make a conclusion.

\subsection{Chemotherapy}

The management of Wilms tumor combines chemotherapy, surgery, and radio 
Table 1. Factors of nephroblastomas' relapses.

\begin{tabular}{|c|c|c|c|c|}
\hline \multirow{2}{*}{$\begin{array}{c}\text { Parameters } \\
\text { Associated malformations }\end{array}$} & \multicolumn{2}{|c|}{ Relapsed } & \multirow[t]{2}{*}{ Total } & \multirow[t]{2}{*}{$\mathrm{p}$} \\
\hline & Yes & No & & \\
\hline Yes & $4(3.12)$ & $1(0.8)$ & $5(3.9)$ & 0.0002 \\
\hline No & $8(6.25)$ & $115(89.8)$ & $123(96.1)$ & \\
\hline \multicolumn{5}{|l|}{ Patients'surgical stories } \\
\hline Operated directly & $3(2.34)$ & 0 & $3(2.34)$ & 0.0006 \\
\hline Operated after chemotherapy & $9(7.03)$ & $116(90.63)$ & $125(97.66)$ & \\
\hline \multicolumn{5}{|l|}{ Neoadjuvant chimiotherapy } \\
\hline Yes & $9(7.07)$ & $116(90.63)$ & $125(97.66)$ & 0.0006 \\
\hline No & $3(2.34)$ & 0 & $3(2.34)$ & \\
\hline \multicolumn{5}{|l|}{ Number of chemotherapy sessions } \\
\hline$<4$ & $7(5.5)$ & $5(3.9)$ & $12(9.4)$ & 0.0000 \\
\hline$\geq 4$ & $5(3.9)$ & $111(86.7)$ & $116(90.6)$ & \\
\hline \multicolumn{5}{|l|}{ Tumor resection } \\
\hline Completed & $7(5.5)$ & $116(90.63)$ & $123(96.1)$ & 0.0000 \\
\hline Non completed & $5(3.9)$ & 0 & $5(3.9)$ & \\
\hline \multicolumn{5}{|l|}{ Preoperative tumor rupture } \\
\hline Yes & $3(2.34)$ & $1(0.8)$ & $4(3.12)$ & 0.0024 \\
\hline No & $9(7.03)$ & $115(89.8)$ & $124(96.88)$ & \\
\hline \multicolumn{5}{|l|}{ Capsular Damage } \\
\hline Yes & $3(2.34)$ & $6(4.7)$ & $9(7.03)$ & 0.0387 \\
\hline No & $9(7.03)$ & $110(85.9)$ & $119(92.97)$ & \\
\hline \multicolumn{5}{|l|}{ Surgical Stage } \\
\hline I & 0 & $42(32.81)$ & $42(32.81)$ & \\
\hline II & $3(2.34)$ & $52(40.7)$ & $55(42.97)$ & \\
\hline III & $6(4.7)$ & $12(9.4)$ & $18(14.1)$ & 0.0003 \\
\hline IV & $3(2.34)$ & $9(7.03)$ & $12(9.4)$ & \\
\hline $\mathrm{V}$ & 0 & $1(0.8)$ & $1(0.8)$ & \\
\hline
\end{tabular}

therapy. Surgery is always preceded by chemotherapy to reduce the tumor mass, facilitate its excision and reduce hemorrhage as well as the risk of swarming of malignant cells [14]. This chemotherapy is started on clinical and radiological arguments in the protocol of Franco-African Group of Oncology. The well-coded protocol depends on the form (localized or metastatic). Non-compliance with the protocol (molecule and number of treatments) negatively influenced the occurrence of recurrences $(p<0.05)$. Neoadjuvant chemotherapy was not performed in 3 of our patients and all of them experienced recurrences. After the diagnosis of renal tumor these three patients were immediately operated on by adult urol- 
ogists outside of Bamako who were unaware of the existence of the protocol. In our series a total of 12 patients didn't follow correctly the four sessions of neoadjuvant chemotherapy and a relapse appeared in seven of them.

Post-operative chemotherapy aims to reduce the incidence of secondary metastases and local recurrences. The duration and modalities of postoperative chemotherapy depend on the extent of the lesions, the quality of their resection and the extent of the associated nephroblastomatosis [5]. Only three of our patients didn't follow a correct protocol of post-operative chemotherapy and two of them returned with relapse.

\subsection{Surgery}

Nephro-ureterectomy with lymph node dissection is the essential time in the treatment of Wilms tumor. Incomplete resection or tumor rupture increases the risk of recurrence and metastasis [15]. We recorded 3.9\% of incomplete resection because of vascular invasion (aorta and vena cava). The tumor was accidentally ruptured when the child fell in $3.1 \%$, but relapse occurred in $2.34 \%$ of cases. A capsular break-in occurred in $7.03 \%$ of patients due to peri-operative difficulties, but a relapse has been noted in $2.34 \%$. These 3 factors were decisive in the occurrence of recurrences $(p<0.05)$.

\subsection{Tumor Surgical Stage}

The progression stage of nephroblastoma is evaluated after surgery. The prognosis is poor as the stage rises. For Brok J et al. [8] stage III and V are considered as risk factors. The surgical stage was decisive in the occurrence of recurrences ( $p<$ 0.05). We did not notice any complication or death.

\section{Conclusion}

Nephroblastoma relapse is not a rare event. The recurrence factors are mainly linked to the treatment and the presence of associated malformation. Compliance with protocols could reduce the frequency of these recurrences. A large sample would allow a conclusion to be drawn in relation to these factors.

\section{Conflicts of Interest}

The authors declare no conflicts of interest regarding the publication of this paper.

\section{References}

[1] Dubois, R. and Chapuis, J.-P. (1998) Tumeur abdominale de l'enfant: Orientation diagnostique. La Revue du Praticien, 48, 2057-2063.

[2] Gleason, J.M., Lorenzo, A.J., Bowlin, P.R. and Koyle, M.A. (2014) Innovation in the Management of Wilms Tumor. Therapeutic Advances in Urology, 6, 165-176. https://doi.org/10.1177/1756287214528023

[3] Varlet, F., et al. (2014) Laparoscopic Treatment of Renal Cancer in Children: A Multicentric Study and Review of Oncologic and Surgical Complications. J Pediatr 
Urol., 10, 500-505.

[4] Audry, G. and Helardot, P.G. (2008) Chirurgie du néphroblastome associés à de la nephroblastomatose (23 Patients). Archives de Pédiatrie, 15, 888. https://doi.org/10.1016/S0929-693X(08)71956-0

[5] Fondation lutte contre le cancer. Nephroblastome. http://www.cancer.be

[6] Brown, E., Hebra, A., Jenrette, J. and Hudspreth, M. (2010) Successful Treatment of Late Recurrent Wilms Tumor with High-Dose Chemotherapy and Autologous Stem Cell Rescue in Third Complete Response. Pediatric Hematology and Oncology, 32, 241-243. https://doi.org/10.1097/MPH.0b013e3181e5e25b

[7] Aoba, T., et al. (2012) Relapse of Unilateral Favorable Histology Wilms' Tumor: Significant Clinicopathological Factor. Journal of Pediatric Surgery, 47, 2210-2215. https://doi.org/10.1016/j.jpedsurg.2012.09.010

[8] Brok, J., Lopez-Yurda, M., Tinteren, H.V., Treger, T.D., Furtwangler, R. and Graft, N. (2018) Relapse of Wilms' Tumor and Detection Methods: A Retrospective Analysis of 2001 Renal Tumor Study Group-International Society of Paediatric Oncology Wilms' Tumor Protocol Database. Lancet Oncology, 19, 1072-1081. https://doi.org/10.1016/S1470-2045(18)30293-6

[9] Rodriguez, I.P., Sarano, D.A., Rodriguez, C.L., Balaguer, G.J., Povo, M.I., Dominiguez, H.C. and Boronat, T.F. (2018) Nephroblastoma: Long-Term Experience in Multidisciplinary Approach. Cirugía Pediátrica, 31, 46-51.

[10] Gallego-Melcon, S., Sanchez de Toledo, J., Doste, D., Lopez, D., Moraga, F., Rodriguez, C., et al. (1994) Late Recurrent Metastasis in Wilms Tumor. Medical and Pediatric Oncology, 23, 158-161. https://doi.org/10.1002/mpo.2950230218

[11] Scott, R.H., Stiller, C.A. and Rahman, N. (2006) Syndromes and Constitutional Chromosomal Abnormalities Associated with Wilms Tumor. Journal of Medical Genetic, 43, 705-715. https://doi.org/10.1136/jmg.2006.041723

[12] Ng, A., Griffiths, A., Cole, T., Davison, V., Griffiths, M., Larkin, S., Parkes, S.E., Mann, J.R. and Grundy, R.G. (2007) Congenital Abnormalities and Clinical Features Associated with Wilms Tumor: A Comprehensive Study from a Centre Serving a Large Population. European Journal of Cancer, 43, 1422-1429. https://doi.org/10.1016/j.ejca.2007.03.020

[13] Dumoucel, S., Gauthier-Villars, M., Stoppa-Lyonnet, D., Parisot, P., Brisse, H., Philippe-Chomette, P., Sarnacki, S., Boccoum-Gibod, L., Rossignol, S., Baumann, C., Aerts, I., et al. (2014) Malformation, Genetic Abnormalities, and Wilms Tumor. Pediatric Blood \& Cancer, 61, 140-144. https://doi.org/10.1002/pbc.24709

[14] Hesseling, P.B., Bardin, R., Brown, J.A., et al. (2019) Wilms Tumor: Long Term Survival of Patients Treated at Mbingo Baptist Hospital in Cameroon between 2007 and 2012. South African Journal of Oncology, 3, a88. https://doi.org/10.4102/sajo.v3i0.88

[15] Doghri, R., Aloui, A., Boujelbene, N., Driss, M., Abess, I., Fdhila, F., Charfi, L., Mezlini, A. and Mread, K. (2018) Analysis of Pronostic Factors of Nephroblastoma in Tunisian Cohort. La Tunisie Médicale, 96, 193-202. 